\title{
Optimization for Deployable Antenna in Condition with Working State
}

\author{
Guoqiang You \\ Xi'an FANYI University, Xi'an, 710105, China \\ simonyouyou@163.com
}

Keywords: Optimization; Deployable antenna; Cable tension; Optimum mathematic model; Genetic algorithm

\begin{abstract}
In this paper, the structure of a large spaceborn deployable antenna is optimized in condition with its working state. The main aim is to obtain the lightest antenna's weight for lower costs. In the optimization process, the optimum mathematic model is established with outer radius of antenna's beam elements and cable tensions as variables, surface precision and natural frequency as constrains, and antenna's weight as objective. Based on the finite element analysis, a genetic algorithm is used to solve this nonlinear mathematic model. And results of example show that this optimization method can effectively reduce antenna's weight as well as keep antenna's structural properties satisfied.
\end{abstract}

\section{Introduction}

The developing space technologies have been increasing the demands for spacecraft high-gain and large-aperture antennas. At the same time, however, low mass is emphasized on these antennas, in order to reduce payload weigh, and to thus reduce launch cost. To meet these goals, large aperture antennas must be deployable.

There have been studies for space antenna structural design. Among those are mainly three groups, such as rigid-surface antenna, mesh-surface antenna and inflatable antenna [1,2].

As far as the mesh-surface antenna is concerned, it has been favored, since 1960's, for its potential fill large apertures with extremely lightweight hardware. Several kinds of design concepts have been proposed [3, 4]. A typical one is called Astromesh deployable antenna. It embodies a new concept for deployable space structure: a pair of ring-stiffened, geodesic truss domes, in which the ring is a truss deployed by a single cable. With a similar idea, an improved design of a 17-m-diameter cable-mesh surface antenna (Fig. 1) is proposed here. There are two deferent points from that. One is the surround truss shown in Fig. 2 to increase the stiffness and the other is an added center tub to avoid the possible

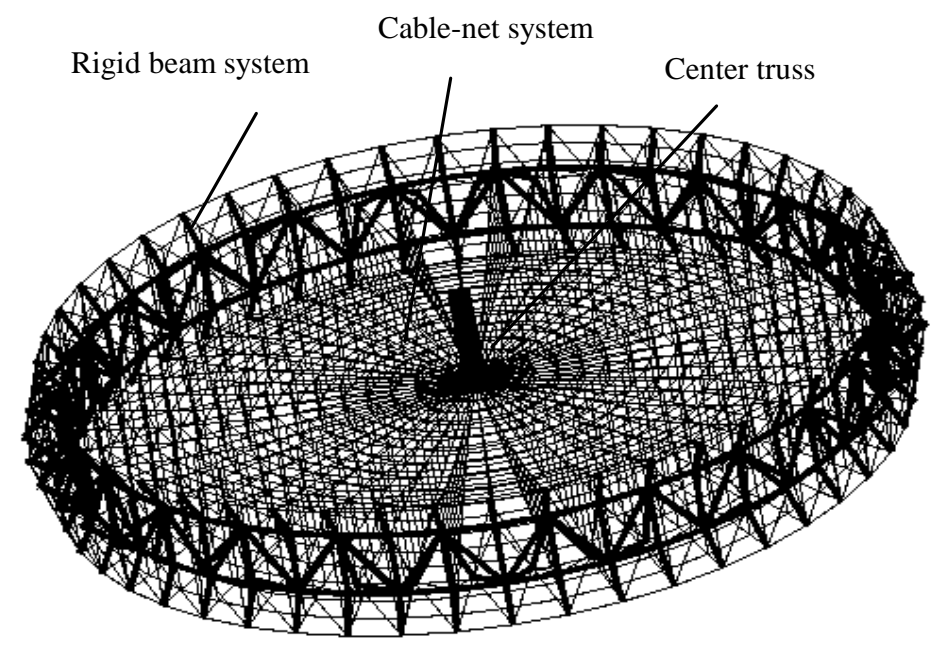

Figure 1. Global antenna structure 


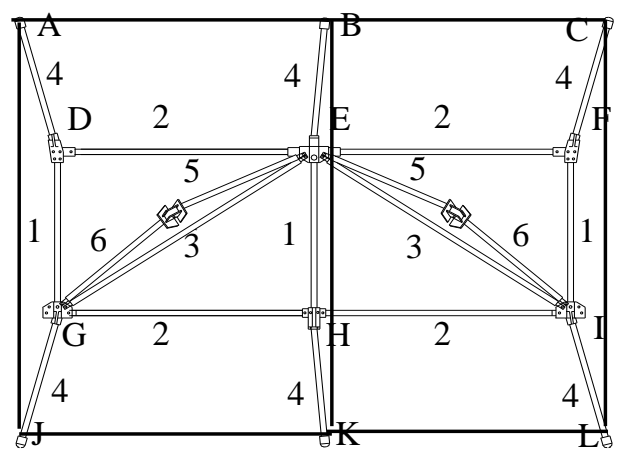

Figure 2. Two deployable truss elements of the surround truss and variable linking

Tied up of the cables. After entering space orbit, the center tub is thrown away automatically. The reflector is composed of 48 radiate-cable beams. These radiate-cable beams are connected and tight with the surround truss and a center tub. In order to have a parabolic shape of the up cable, vertical adjusting cables are mounted between the up and bottom ones. To avoid tied up between radiate-cable beams, there are no cables between the radiate-cable beams.

Unfortunately, few papers concern optimization of cable-mesh surface antenna. In addition, there is little report dealt with the problem of optimization for space antenna with deployed states. This paper intends to deal with the problem.

\section{Analysis Method and Optimization Modeling of Structure}

Finite Element Model. The cable-mesh antenna contains three main parts as stated previously, shown in Fig. 1. The surround truss is composed of 48 deployable truss elements (DTE). Each DTE comprises with 8 bars. For each DTE, there are 3 vertical bars, 2 horizontal bars and 3 diagonal bars linked to the adjacent DTE, Fig. 3. A DTE can be deployed and retracted by the diagonal bars 5 and 6 . All these bars are considered as 2-node beam elements and therefore 384 beams totally.

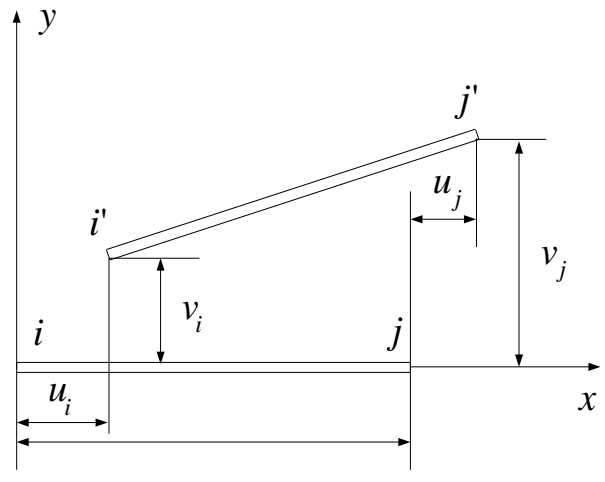

Figure 3. Two node element

The cable-mesh contains 48 radiate-cable beams, each one contains 17 up cables, 17 bottom cables and 16 vertical cables. In addition, there are three cables for each DTE (A-B, A-J and J-K) as shown in Fig. 3, so that totally 144 cables for the surround truss. All of these cables are taken as cable-bar elements, which cannot be compressed, 2544 cable-bar elements in all. The center tub is divided into 960 triangular shell elements.

In deployed state, the antenna is connected to satellite with two points of only one radiate-cable beam, say points D and G, or E and H, or F and I (Fig. 3).

Form-finding Methods for Cable-net Structure. The deployable antenna discussed in this paper is a large cable-truss system, and the cable-net in it is flexible structure. Only when prestress is put on, by static equilibrium, the cable-net will has the given geometrical shape, and this process is called 
form-finding. In addition, the stiffness of structure and the position of cable are all closely related with the value and distribution of given prestress. Because of the large deformation will be induced by the prestress put on cable-net, the form-finding of structure is a geometrical nonlinear problem. Some numerical methods are thought to be effective for determining the internal force distribution and initial shape of cable-net structure, they are force density method, nonlinear finite element method and dynamic relaxation method. In this paper, nonlinear finite element method is selected as the analysis method for the form-finding [5,6]. The reason is that, compared with the other methods, it not only can give the influence caused by the change of material property and temperature environment, but also can be used for the dynamic analysis of the structure $[7,8]$.

There is no gravity in space, so the cable will be a straight line when the prestress is put on it. Thinking of this, a kind of bar element with two nodes is used to replace the cable structure(Fig. 3 ).

The axial strain of the element can be calculated out by the nonlinear strain-displacement equation,

$$
\varepsilon_{x}=\frac{\partial u}{\partial x}+\frac{1}{2}\left(\frac{\partial v}{\partial x}\right)^{2}
$$

Based on this, the deformation energy of the element can be introduced,

$$
U^{e}=\frac{1}{2} \int_{V} E \varepsilon_{x}^{2} d V
$$

Hooke law still works as follow,

$$
F=E A \frac{\partial u}{\partial x}
$$

Nodal displacement matrix of the element is

$$
\delta^{e}=\left[\begin{array}{llll}
u_{i} & v_{i} & u_{j} & v_{j}
\end{array}\right]^{T}
$$

Then the displacement of any point in element can be get by the nodal displacement,

$$
\{u\}=\left\{\begin{array}{l}
u \\
v
\end{array}\right\}=\left\{\begin{array}{l}
{\left[N_{u}\right]} \\
{\left[N_{v}\right]}
\end{array}\right\}\{\delta\}^{e}=[N]\{\delta\}^{e}
$$

In which, $[N]=\left\{\begin{array}{l}{\left[N_{u}\right]} \\ {\left[N_{v}\right]}\end{array}\right\}$ is the shape function matrix.

The nonlinear finite element equation can be obtained according to the principle of virtual work,

$$
\left(\left[K_{E}\right]^{e}+\left[K_{G}\right]^{e}\right)\{\delta\}^{e}=\{P\}-\{R\}
$$

In which,

$$
\begin{aligned}
& {\left[K_{E}\right]^{e}=E A \int_{-l}^{l}\left(\frac{\partial\left[N_{u}\right]}{\partial x}\right)^{T} \frac{\partial\left[N_{u}\right]}{\partial x} d x} \\
& {\left[K_{G}\right]^{e}=F \int_{-l}^{l}\left(\frac{\partial\left[N_{v}\right]}{\partial x}\right)^{T} \frac{\partial\left[N_{v}\right]}{\partial x} d x}
\end{aligned}
$$

In the formulae (7), $A$ is the cross-sectional area of cable element, $\left\{K_{E}\right\}^{e}$ is the elastic stiffness matrix of element, $\left\{K_{G}\right\}^{e}$ is the geometrical nonlinear stiffness matrix of element, $\{P\}$ is the equivalent nodal external force matrix of element, $\{R\}$ is the equivalent nodal force matrix of element.

Formulae(6) is a nonlinear equation, in order to obtain relatively high speed and accuracy in the process of calculation, Newton-Raphson method is used to solve the problem.

Optimization Model. To be the first, optimization model with design variable, objective function and constraints needs to be discussed. 
The cross-sectional areas of 8 bars for each DTE can be linked to 6 independent design variables (shown in Fig. 2), i.e., $\mathrm{A}=(\mathrm{A} 1, \mathrm{~A} 2, \ldots, \mathrm{AN}) \mathrm{T}$ and $\mathrm{N}=6$ according to symmetry, manufacturing and so on. Since 48 DTEs are all the same for surround truss, the total 384 beams are also finally linked to 6 independent design variables. In order to have enough stiffness, cable tension distribution needs to be optimized. Thus it is considered as design variable. Since the up and bottom cables are symmetry with respect to the horizontal line $\mathrm{X}$ and without of the earth gravitation, total independent cable tension variables will be $\mathrm{F}=(\mathrm{F} 1, \mathrm{~F} 2, \ldots, \mathrm{FM}) \mathrm{T}$ with $\mathrm{M}=48$.

The objective can be structural mass, reflector precision or natural frequency of antenna. Sometimes, they can be all taken as objective function. In this paper, structural mass is taken as objective function $[9,10]$.

For constrains, when antenna is in working state in its orbit, reflector's precision cannot be over the allowable limit. The natural frequency should be larger than or equal to the given value [11]. The stresses of all elements are asked to be within the permissible strength of material.

Considering the above discussion synthetically leads us to the following optimum mathematic model,

$$
\begin{aligned}
& \text { find } \mathrm{A}=(\mathrm{A} 1, \mathrm{~A} 2, \ldots, \mathrm{AN}) \mathrm{T} \text { and } \mathrm{F}=(\mathrm{F} 1, \mathrm{~F} 2, \ldots, \mathrm{FM}) \mathrm{T} \\
& \min W=\sum_{i=1}^{N} A_{i} \sum_{j \in i} l_{i j}+W_{0} \\
& \text { s.t. } \quad g_{1}(A, F)=D-D^{L}=\left[\frac{1}{N U P} \sum_{i=1}^{N U P} \delta_{i z}^{2}\right]^{1 / 2}-D^{L} \leq 0 \\
& g_{2 e}(A, F)=\sigma_{e}-\left[\sigma_{\text {truss }}\right] \leq 0, \quad(\mathrm{e}=1,2, \mathrm{TNUM}) \\
& g_{3 \gamma}(A, F)=\sigma_{\gamma}-\left[\sigma_{\text {cable }}\right] \leq 0, \quad(\gamma=1,2, \cdots, C N U M) \\
& \quad g_{4}(A, F)=-\omega+\underline{\omega} \leq 0 \\
& \quad A_{i} \in\left[A^{L}, A^{U}\right],(\mathrm{i}=1,2, \ldots, \mathrm{N}) \\
& F_{i} \in\left[F^{L}, F^{U}\right],(\mathrm{i}=1,2, \ldots, \mathrm{M})
\end{aligned}
$$

In which, $\mathrm{W}$ is the mass of surround truss. ${ }^{W_{0}}$ is the mass of center tub and cable-mesh that remain constant during iteration. ${ }_{i j}$ is the total length of those bars controlled by the ith cross-sectional area Ai of the surround tube truss. $D$ and $D^{L}$ denote the real reflector error in terms of rms value and permissible value respectively. $\sigma_{e}$ and $\left[\sigma_{\text {truss }}\right]$ are, respectively, the real stress of the eth bar element and the allowable maximum value. ${ }^{\sigma_{\gamma}}$ and $\left[\sigma_{\text {cable }}\right]$ are the real tension stress of the $\gamma$ th cable bar element and the corresponding permissible value respectively. ${ }^{\omega}$ and $\underline{\omega}$ are natural frequency and the allowable maximum value respectively. $A_{i}^{U}$ and $A_{i}^{L}$ are, separately, the upper and lower bounds of Ai. Likely, $F_{j}^{U}$ and $F_{j}^{L}$ are the upper and lower bounds of jth cable tension respectively.

This mathematic model is a high nonlinear programming problem with three special points: nonlinear of structure itself, particularly geometric nonlinear of the cable, behavior constraints being high nonlinear functions, both cable tension and cross-sectional area with different dimensions and metric.

The first characteristic is the structural inherent characteristic, to which we have to face. As for the second and the third, there are two choices. One is to make Taylor expansion of constraints, so that the original nonlinear programming problem is transformed into a series of linear programming problems. 
The other is to utilize direct approach to deal with the original problem directly. Here genetic algorithm is utilized.

\section{Numerical Experiment and Discussion}

The parameters of cable-mesh surface antenna structure in Fig. 1 are as follows. The diameter is $17 \mathrm{~m}$ and the height of reflector is $1.3894 \mathrm{~m}$. Structural material except for cable is the carbon fibre with elastic modulus $2.35 \times 1011 \mathrm{~N} / \mathrm{m} 2$. The thickness of the tube bar for the surround truss is $0.5 \mathrm{~mm}$. Parameters of the cable-mesh are with the elastic modulus $1.24 \times 1011 \mathrm{~N} / \mathrm{m} 2$ and cable cross-sectional diameter $0.002 \mathrm{~m}$ separately. As for the center tub, it is $2.2 \mathrm{~m}$ in height, $0.4 \mathrm{~m}$ in diameter, and $0.001 \mathrm{~m}$ in thickness, respectively.

In the working state, the required value (rms) of reflector error away from the corresponding parabolic reflector is less than $3.5 \mathrm{~mm}$. The minimum natural frequency of antenna structure is required to be larger than or equal to $0.7 \mathrm{~Hz}$. The lower and upper bounds of the cross-sectional outer radius are $[0.0015,0.03](\mathrm{m})$. The lower and upper bounds of the cable tensions are $[0,1000](\mathrm{N})$.

By experiencing numerical computation, the structural mass iteration history is shown in Fig. 4.

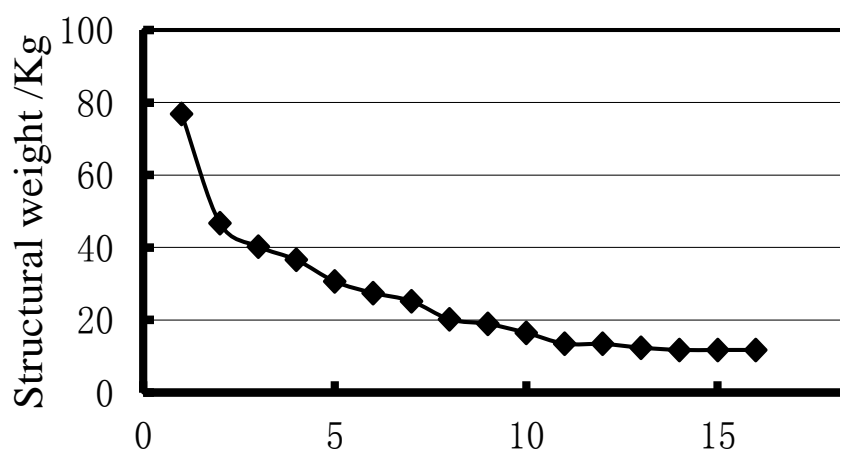

Figure 4. Iteration history of objective function

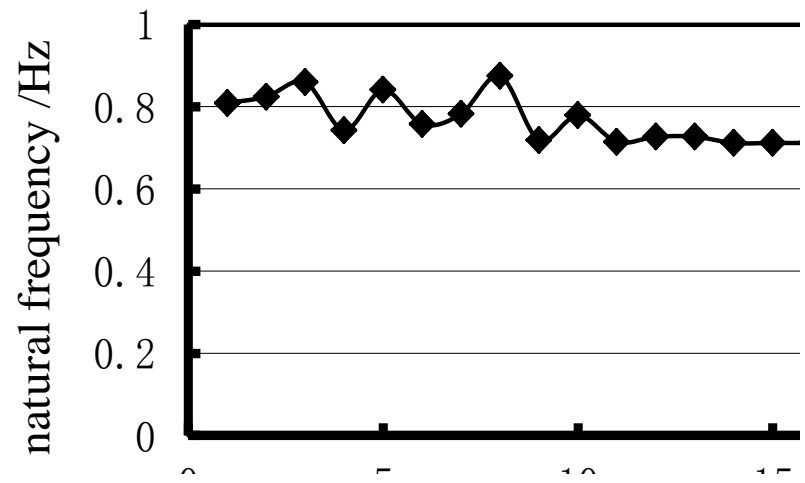

Figure 5. Iteration history of natural frequency

Table 1 The final result of cross-sectional outer radius

\begin{tabular}{|c|c|c|c|c|c|}
\hline Variable No. & Variable value & Variable No. & Variable value & Variable No. & Variable value \\
\hline 1 & $6.806 \mathrm{e}-3[\mathrm{~m}]$ & 3 & $1.5 \mathrm{e}-3[\mathrm{~m}]$ & 5 & $10.21 \mathrm{e}-3[\mathrm{~m}]$ \\
\hline 2 & $1.5 \mathrm{e}-3[\mathrm{~m}]$ & 4 & $8.919 \mathrm{e}-3[\mathrm{~m}]$ & 6 & $1.5 \mathrm{e}-3[\mathrm{~m}]$ \\
\hline
\end{tabular}

Table 2 The final result of cable tension

\begin{tabular}{|c|c|c|c|c|c|}
\hline Variable No. & Variable value & Variable No. & Variable value & Variable No. & Variable value \\
\hline 1 & $6.18 \mathrm{E}+02[\mathrm{~N}]$ & 17 & $5.7258 \mathrm{e}+2[\mathrm{~N}]$ & 33 & $5.9838 \mathrm{e}+2[\mathrm{~N}]$ \\
\hline 2 & $5.8225 \mathrm{e}+2[\mathrm{~N}]$ & 18 & $5.758 \mathrm{e}+2[\mathrm{~N}]$ & 34 & $5.887 \mathrm{e}+2[\mathrm{~N}]$ \\
\hline 3 & $5.758 \mathrm{e}+2[\mathrm{~N}]$ & 19 & $6.5645 \mathrm{e}+2[\mathrm{~N}]$ & 35 & $5.9516 \mathrm{e}+2[\mathrm{~N}]$ \\
\hline 4 & $6.2096 \mathrm{e}+2[\mathrm{~N}]$ & 20 & $6.2741 \mathrm{e}+2[\mathrm{~N}]$ & 36 & $6.0161 \mathrm{e}+2[\mathrm{~N}]$ \\
\hline 5 & $6.1129 \mathrm{e}+2[\mathrm{~N}]$ & 21 & $5.6935 \mathrm{e}+2[\mathrm{~N}]$ & 37 & $6.3387 \mathrm{e}+2[\mathrm{~N}]$ \\
\hline 6 & $6.2096 \mathrm{e}+2[\mathrm{~N}]$ & 22 & $5.9838 \mathrm{e}+2[\mathrm{~N}]$ & 38 & $6.0806 \mathrm{e}+2[\mathrm{~N}]$ \\
\hline 7 & $5.758 \mathrm{e}+2[\mathrm{~N}]$ & 23 & $5.8225 \mathrm{e}+2[\mathrm{~N}]$ & 39 & $6.5322 \mathrm{e}+2[\mathrm{~N}]$ \\
\hline 8 & $6.3709 \mathrm{e}+2[\mathrm{~N}]$ & 24 & $6.0161 \mathrm{e}+2[\mathrm{~N}]$ & 40 & $5.758 \mathrm{e}+2[\mathrm{~N}]$ \\
\hline 9 & $6.5645 \mathrm{e}+2[\mathrm{~N}]$ & 25 & $5.8838 \mathrm{e}+2[\mathrm{~N}]$ & 41 & $6.0483 \mathrm{e}+2[\mathrm{~N}]$ \\
\hline 10 & $5.887 \mathrm{e}+2[\mathrm{~N}]$ & 26 & $6.5677 \mathrm{e}+2[\mathrm{~N}]$ & 42 & $5.9516 \mathrm{e}+2[\mathrm{~N}]$ \\
\hline 11 & $6.4354 \mathrm{e}+2[\mathrm{~N}]$ & 27 & $5.7903 \mathrm{e}+2[\mathrm{~N}]$ & 43 & $5.7903 \mathrm{e}+2[\mathrm{~N}]$ \\
\hline 12 & $5.758 \mathrm{e}+2[\mathrm{~N}]$ & 28 & $6.2741 \mathrm{e}+2[\mathrm{~N}]$ & 44 & $6.5 \mathrm{e}+2[\mathrm{~N}]$ \\
\hline 13 & $5.8548 \mathrm{e}+2[\mathrm{~N}]$ & 29 & $6.4677 \mathrm{e}+2[\mathrm{~N}]$ & 45 & $6.0483 \mathrm{e}+2[\mathrm{~N}]$ \\
\hline 14 & $5.9516 \mathrm{e}+2[\mathrm{~N}]$ & 30 & $5.887 \mathrm{e}+2[\mathrm{~N}]$ & 46 & $6.0483 \mathrm{e}+2[\mathrm{~N}]$ \\
\hline 15 & $5.9516 \mathrm{e}+2[\mathrm{~N}]$ & 31 & $6.2741 \mathrm{e}+2[\mathrm{~N}]$ & 47 & $6.4032 \mathrm{e}+2[\mathrm{~N}]$ \\
\hline 16 & $6.3387 \mathrm{e}+2[\mathrm{~N}]$ & 32 & $5.8225 \mathrm{e}+2[\mathrm{~N}]$ & 48 & $6.2741 \mathrm{e}+2[\mathrm{~N}]$ \\
\hline
\end{tabular}


It can be noted that structural mass is reduced from $76 \mathrm{~kg}$ to $11.8 \mathrm{~kg}$ (by $80 \%$ ), which is much less than the required value of $34 \mathrm{~kg}$. The iteration history of natural frequency is shown in Fig. 5, from which we can notice that frequency constraint is becoming active at the end. The optimization results of the outer radius of cross-section of the surround truss and cable tension are shown in table 1 and 2 respectively.

\section{Conclusions}

Theoretical analysis and numerical experiment of a 17-m diameter cable-mesh surface antenna optimization may lead us to the following conclusions.

A novel optimization model and methodology, which is seldom run into before, for antenna design used in satellite with working states, is proposed and investigated. The comprehensive design model is composed of an optimization model and finite element models corresponding to its working states. The design model is a highly nonlinear programming problem, genetic algorithm is employed to solve the problem finally.

The prestressed cable-mesh structure is utilized to form the reflector of antenna for the purpose of having high ratio of stiffness to weight. In the model, design variable is concerned with cable tension and cross-sectional area of surround truss. The nonlinear constraints include reflector precision, strength of material, frequency and variable sides for working state.

The thermal load in the space is a main factor, which has to be considered for designing the satellite antenna structures. However, this paper is mainly concerned with optimal design model, and thermal analysis is not considered at the moment. Nevertheless, it will be presented late.

The optimization model and result have been applied to the design of a satellite deployable cable-mesh antenna with the diameter of 17 meters with reasonable and useful result. Seeing from the view point of engineering may lead us to that not only the model but also the result is of a certain engineering reference to the designing and manufacturing of the practical space deployable antennas.

\section{Acknowledgements}

Financial supports by Shaanxi Province Department of Education(16JK2076) are gratefully acknowledged.

\section{References}

[1] J. Mitsuji and T. Yasaka, Shape control of the tension truss antenna, AIAA. 28 (1990) 316-322.

[2] M. Misawa, Stiffness design of deployable satellite antennas in deployed configuration, Int. J. Spacecraft and Rockets. 35 (1998) 380-386.

[3] J. Huang, The development of inflatable array antennas, IEEE Transaction on Antennas and Propagation. 43 (2001) 44-50.

[4] T. Takano et. al, Deployable antenna with 10-m maximum diameter for space use, IEEE Transactions on Antennas and Propagation. 52 (2004) 2-11.

[5] M. Koryo and M. Yasuyuki, Concept of the tension truss antenna, AIAA Journal. 28 (1990) 1098-1104.

[6] S. Pellegrino and C. R. Calladine, Matrix analysis of statically and kinematically indeterminate framworks, International Journal of Solids \& Structures. 22 (1986) 409-428.

[7] G. Li and F. Guan, Pretension optimization in parabolic cable net of Astromesh deployable reflector, Journal of Zhejiang University. 39 (2005) 1557-1560. (In Chinese).

[8] D. Yang and H. Bao, Force balance characteristics and pretension design of asymmetric cable net parabolic antenna, Journal of Mechanical Engineering. 45 (2009) 308-312. (In Chinese)

[9] J. Di, B. Duan and Y. Luo, etc, Preloading optimization of large net-shape deployable antennas, Journal of South China University of Technology. 32 (2004) 23-26. (In Chinese). 
[10]M. Kaminski and B. Schrefler, Probabilistic effective characteristics of cables for super conducting coils, Computer Methods in Applied Mechanics and Engineering. 188 (2000) 1-16.

[11]N. Vassart and R. Motro, Multipara metered form finding method: Application to tensegrity systems, International Journal of Space Structures. 14 (1999) 147-154. 